\title{
THE IDENTIFICATION OF PSEUDOMONADS AND RELATED BACTERIA IN A CLINICAL LABORATORY
}

\author{
AnNa King AND I. Phillips \\ Department of Microbiology, St Thomas's Hospital Medical School, London SE1 7EH
}

Despite the inclusion of tables for the identification of pseudomonads and other non-fermenting organisms in the latest edition of Cowan and Steel's Manual for the identification of medical bacteria (Cowan, 1974) many clinical laboratories lack the confidence and experience to attempt the task. Since 1970, we have attempted to identify all Gram-negative organisms isolated from patients and enviromental sites in our Intensive Care Unit, and our experiences are now recorded.

\section{MATERIALS AND METHODS}

Bacteria. The organisms were obligate or facultative aerobes isolated from clinical or environmental samples from the Intensive Care Unit, St Thomas' Hospital. The medium of primary isolation was almost invariably blood agar (Oxoid Blood Agar Base No. 2, code CM271, with 6-7\% defibrinated horse blood) incubated aerobically. Some organisms, particularly those from urine, were isolated on C.L.E.D. Medium (Oxoid, CM301) and a few were isolated on nutrient agar or from blood cultures in nutrient broth containing glucose $0 \cdot 1 \%, p$-aminobenzoic acid and sodium polyanethol sulphonate (Liquoid) (Southern Group Laboratories). All grew on subculture on nutrient agar.

Organisms were also obtained for comparison from the collections of the Center for Disease Control (Atlanta) and the National Collection of Type Cultures, Colindale.

Methods of identification. Most of the methods used have been listed in Cowan and Steel's Manual (Cowan, 1974) and we therefore refer to the methods in the Manual but give neither details of these, nor references to original work. Other methods, not included in the Manual, are given in more detail.

The first four tests, performed for all isolates, were the oxidation-fermentation (OF) test of Hugh and Leifson with glucose as the substrate, Kovac's oxidase test, the catalase test on a nutrient agar slope, and a test for motility in which suspensions of 6-h peptone-water cultures at room temperature and at $37^{\circ} \mathrm{C}$ were examined on a slide under a coverslip by phase-contrast microscopy. It was important to appreciate that cultures of certain motile species contained only a small proportion of motile organisms.

Tests for carbohydrate metabolism were performed with Difco ammonium salt " sugars " (adonitol, arabinose, cellobiose, dulcitol, ethanol, fructose, galactose, glucose, glycerol, inositol, inulin, lactose, maltose, mannitol, mannose, raffinose, rhamnose, salicin, sorbitol, sucrose, trehalose, xylose). Cowan and Steel's method 4 was used except that the final concentration of bromocresol purple was $0.004 \%(\mathrm{w} / \mathrm{v})$ and that glucose and arabinose were used also as peptone-water sugars with Andrade's indicator. Weused Carpenter's modification of Shaw and Clark's method for gluconate reduction in 2-ml volumes of medium, and the ONPG test for $\beta$-galactosidase activity.

Other tests used included the following: hydrolysis of aesculin, arginine (method 2, Thornley), casein, gelatin, Tweens 20 and 80, tyrosine, and urea; growth on Simmons'

Received 6 Sept. 1977; accepted 21 Oct. 1977.

J. MED. MICROBIOL.-VOL. 11 (1978) 
citrate medium, on MacConkey agar, on $\beta$-hydroxybutyrate medium (with or without accumulation of poly- $\beta$-hydroxybutyrate) (Owens and Keddie, 1968), in potassium cyanide broth, and in Nutrient Broth (Southern Group Laboratories) at $4^{\circ} \mathrm{C}$, room temperature and $42^{\circ} \mathrm{C}$; the decarboxylation of arginine, lysine and ornithine (method 1 , Møller) in which a simple change to an alkaline reaction was positive; the production of hydrogen sulphide in TSI (method 1, modified by the omission of sugars and indicator), of indole (method 2, Kovacs), and of pigments on nutrient agar, King's media $\mathbf{A}$ and $\mathbf{B}$, and tyrosine agar; the reduction of nitrate (method 1) and nitrite; the utilisation of malonate and deamination of phenylalanine by the combined method of Shaw and Clark (method 1).

It is important that all tests were carried out after the recommended time. Attempts at short cuts led to considerable confusion.

The antibiotic sensitivity of each isolate was determined by a disk method on lysed-blood agar (Oxoid DST Agar, code CM261, with 5\% saponin-lysed horse blood) for the following agents: ampicillin (disk content $25 \mu \mathrm{g})$, carbenicillin $(100 \mu \mathrm{g})$, cephalexin $(30 \mu \mathrm{g})$, cephaloridine $(25 \mu \mathrm{g})$, cephalothin $(30 \mu \mathrm{g})$, chloramphenicol $(50 \mu \mathrm{g})$, colistin (100 units), cotrimoxazole (total $25 \mu \mathrm{g})$, gentamicin $(10 \mu \mathrm{g})$, kanamycin $(30 \mu \mathrm{g})$, neomycin $(30 \mu \mathrm{g})$, sulphafurazole (500 $\mu \mathrm{g})$, and tetracycline $(50 \mu \mathrm{g})$. Results were expressed as sensitive, intermediate or resistant

TABLE I

Sources of organisms

\begin{tabular}{|c|c|c|c|c|c|c|}
\hline \multirow{3}{*}{$\begin{array}{c}\text { Final } \\
\text { identification }\end{array}$} & \multicolumn{5}{|c|}{ Number of isolates from } & \multirow{3}{*}{$\begin{array}{c}\text { Total } \\
\text { number } \\
\text { of } \\
\text { isolates }\end{array}$} \\
\hline & \multicolumn{2}{|c|}{ St Thomas' Hospital } & \multirow{2}{*}{ NCTC } & \multirow{2}{*}{$\begin{array}{c}\text { NCTC } \\
\text { Computer } \\
\text { Trials } \\
\text { Laboratory }\end{array}$} & \multirow{2}{*}{$\begin{array}{c}\text { Center for } \\
\text { Disease } \\
\text { Control, } \\
\text { Atlanta }\end{array}$} & \\
\hline & Patients & Environment & & & & \\
\hline \multicolumn{7}{|l|}{ Pseudomonas } \\
\hline $\begin{array}{l}\text { acidovorans } \\
\text { aeruginosa }\end{array}$ & 9 & 11 & 1 & $\ldots$ & 1 & 22 \\
\hline $\begin{array}{l}\text { aeruginosa } \\
\text { alkaligenes }\end{array}$ & 12 & 4 & 2 & $\cdots$ & $\dddot{i}$ & $\begin{array}{r}18 \\
2\end{array}$ \\
\hline cepacia & $\dddot{3}$ & 37 & 4 & $\begin{array}{l}\cdots \\
\cdots\end{array}$ & 2 & 46 \\
\hline $\begin{array}{l}\text { diminuta } \\
\text { fuorescens }\end{array}$ & 96 & 0 & 1 & $\ldots$ & 1 & 2 \\
\hline $\begin{array}{l}\text { Thorescens } \\
\text { fragi }\end{array}$ & 16 & 9 & 2 & $\cdots$ & $\cdots$ & 27 \\
\hline mallei & ... & $\cdots$ & 2 & $\cdots$ & $\ldots$ & $\frac{1}{2}$ \\
\hline maltophilia & 38 & 33 & 1 & $\ldots$ & $\ldots$ & 72 \\
\hline $\begin{array}{l}\text { mendocina } \\
\text { ovalis }\end{array}$ & $\cdots$ & $\cdots$ & 2 & $\cdots$ & $\cdots$ & 2 \\
\hline paucimobilis & $\dddot{i}$ & $\dddot{22}$ & $\ldots$ & $\ldots$ & $\ldots$ & 23 \\
\hline pickettii & $\cdots$ & 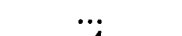 & $\ldots$ & 11 & $\ldots$ & 11 \\
\hline $\begin{array}{l}\text { pseudoalkaligenes } \\
\text { pseudomallei }\end{array}$ & 9 & 4 & 1 & $\cdots$ & $\cdots$ & 14 \\
\hline putida & $\dddot{43}$ & $\ddot{2}$ & 1 & $\cdots$ & $\cdots$ & $\begin{array}{r}2 \\
46\end{array}$ \\
\hline putrefaciens & 1 & $\ldots$ & $\cdots$ & $\ldots$ & $\dddot{2}$ & 3 \\
\hline stutzeri & 1 & $\ldots$ & 3 & $\ldots$ & $\overline{3}$ & 7 \\
\hline $\begin{array}{l}\text { taetrolens } \\
\text { testosteroni }\end{array}$ & $\cdots$ & $\dddot{i}_{i}$ & 1 & $\cdots$ & $\cdots$ & 1 \\
\hline $\begin{array}{l}\text { testosteroni } \\
\text { thomasii }\end{array}$ & $\dddot{34}$ & $\begin{array}{l}1 \\
8\end{array}$ & $\ldots$ & $\dddot{7}$ & 20 & $\begin{array}{r}2 \\
69\end{array}$ \\
\hline $\begin{array}{c}\text { vesiculare } \\
\text { Acinetobacter }\end{array}$ & $\cdots$ & $\ldots$ & 1 & $\ldots$ & 1 & 2 \\
\hline anitratus & 19 & 3 & $\ldots$ & $\ldots$ & $\ldots$ & 22 \\
\hline $\begin{array}{l}\text { lwoffii } \\
\text { Alkaligenes }\end{array}$ & 22 & 2 & $\cdots$ & $\ldots$ & $\ldots$ & 24 \\
\hline $\begin{array}{l}\text { odorans } \\
\text { Flavobacterium sp. }\end{array}$ & $\begin{array}{r}5 \\
\ldots\end{array}$ & $\dddot{2}$ & $\cdots$ & $\cdots$ & $\cdots$ & 5 \\
\hline Totals & 213 & 138 & 27 & 18 & 32 & 428 \\
\hline & & & & 18 & 32 & 428 \\
\hline
\end{tabular}


by reference to the laboratory's standard regression lines relating zone sizes and minimum inhibitory concentrations.

Construction of identification tables. Initially all the investigations listed above were carried out for each organism but eventually tests that gave no useful information were omitted; in this way the final identification tables evolved.

\section{RESULTS}

A total of 428 organisms was included in the initial part of the study in which all the tests above were used. These organisms are listed in table I, as finally identified, along with their sources. The genera represented were Pseudomonas, Acinetobacter, Alkaligenes and Flavobacterium. The name Pseudomonas paucimobilis has been proposed for a collection of strains, some isolated by us, and some-representatives of group IIK, biotype I (Weaver, Tatum and Hollis, 1972; Tatum, Ewing and Weaver, 1974)-by Holmes et al. (1977). Of all the isolates $49 \%$ were from patients and $32 \%$ from evironmental sites in St Thomas' Hospital. The isolates from patients came from respiratory tract secretions ( $31 \%$ ), peritoneal dialysis fluid and catheter sites $(28 \%)$, urine $(25 \%)$, wounds $(11 \%)$ and blood $(5 \%)$.

In the final determinative scheme, three major tests-oxidation-fermentation, oxidase and motility - were performed on all the isolates. All, when tested in Hugh and Leifson's medium, were either oxidative, or produced alkali. Alkali production was sometimes very weak and difficult to detect, as for example with Acinetobacter lwoffi $i$ which produced a thin surface $p \mathrm{H}$ change after $24 \mathrm{~h}$. With other organisms, particularly $P$. maltophilia, the initial strong alkaline reaction sometimes disappeared after incubation for $48 \mathrm{~h}$. Most of the oxidative organisms produced a characteristic reaction within $24 \mathrm{~h}$, that thereafter did not change. Difficulty was encountered with yellowpigmented organisms such as strains of $P$. paucimobilis which soon resembled fermenters as the growth spread through both tubes.

The figure shows the most useful investigations for oxidative, oxidasepositive, motile organisms. Production of a blue, red or brown pigment on King's medium A identified $P$. aeruginosa. The production of a fluorescent pigment on King's medium B was characteristic of most isolates of $P$. putida, $P$. fluorescens and $P$. aeruginosa. Finally the presence or absence of arginine dihydrolase permitted the division of non-pigmented variants of these three species and a variety of other pseudomonads into two groups. Highly mucoid strains of $P$. aeruginosa were usually non-motile, and sometimes non-pigmented.

Table II shows the tests that are most useful in identifying fluorescent (and therefore arginine-positive) pseudomonads. In our experience $P$. aeruginosa was seldom atypical in any of these tests. If confirmatory tests were needed, the best were gluconate (almost always positive), urea (positive after 2-3 days), casein (positive), and gelatin (positive). P. fluorescens produced typical reactions at room temperature. Some isolates reduced nitrate to nitrite, but atypical results were otherwise rare. Confirmatory tests included acid production from rhamnose and sorbitol, and hydrolysis of casein (negative) 
and gelatin (positive). $P$. putida was rarely atypical, except that a few isolates were ethanol-negative. All of the isolates failed to attack casein, gelatin, rhamnose and sorbitol, and produced a pale brown pigment on tyrosine. A few isolates of $P$. fluorescens also produced this pigment but $P$. aeruginosa did not. In addition $P$. putida, and less commonly $P$. fluorescens, produced acid from glucose in peptone water, but $P$. aeruginosa did not.

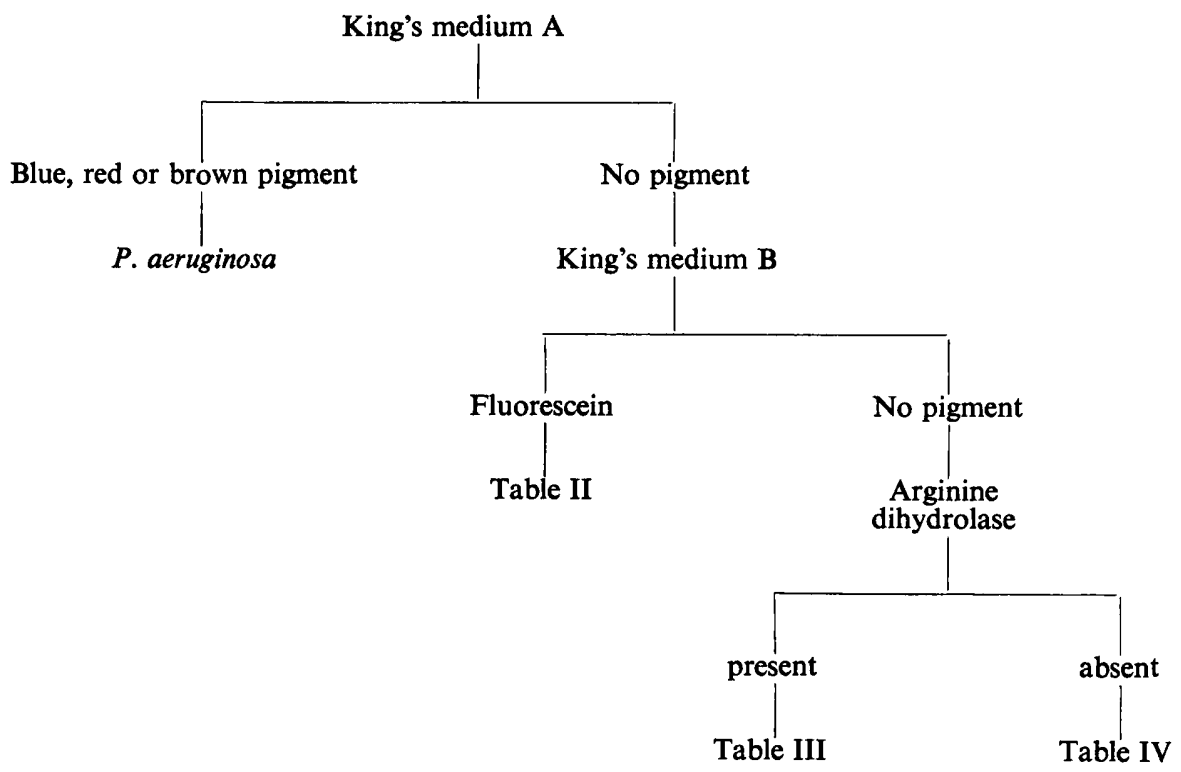

FIGURE.-Useful tests for the identification of organisms that are oxidative, oxidase-positive and motile.

TABLE II

Fluorescent, arginine-positive pseudomonads

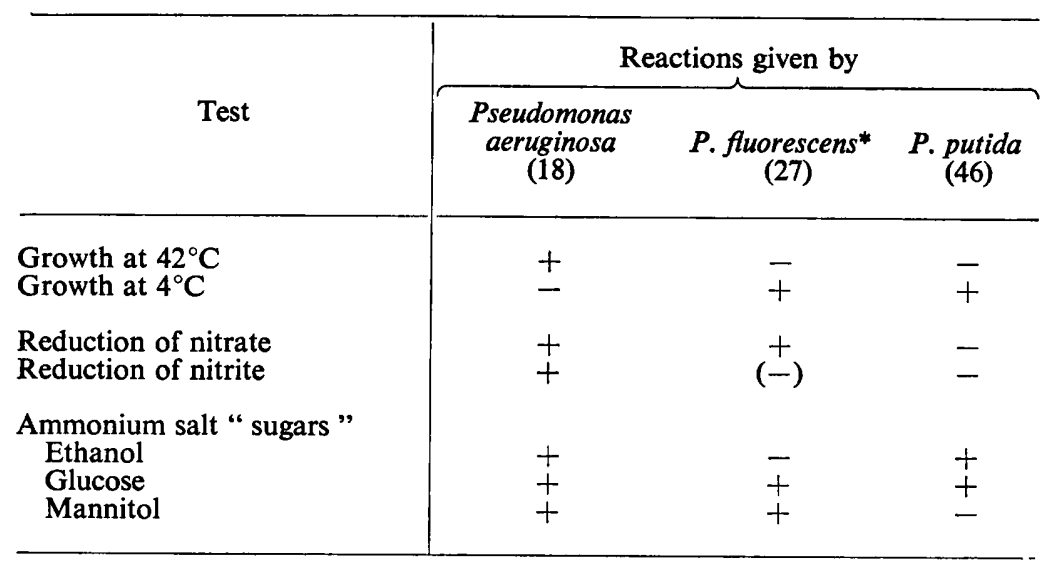

Number of isolates tested is given in parenthesis.

* Typical reactions at room temperature.

$(-)=$ Usually negative. 
Table III lists the characteristic reactions of non-pigmented, argininepositive pseudomonads. It should be noted that results for $P$. fluorescens, $P$. fragi and $P$. taetrolens were obtained at room temperature. We examined only two strains of $P$. pseudomallei, both from the National Collection of Type Cultures, and had no difficulty in distinguishing them on the basis of the listed tests. In addition the colonies of both were of a distinctive pale cream colour. $P$. ovalis, $P$. mendocina, $P$. fragi and $P$. taetrolens were not seen in clinical material. The P. stutzeri strains were usually arginine-negative and all had characteristic flat wrinkled colonies.

Table IV shows characteristic results for oxidative, oxidase-positive, arginine-negative organisms. Colony pigmentation was a useful characteristic of certain organisms in this group: $P$. paucimobilis strains were particularly brightly-yellow pigmented, whilst the two $P$. vesiculare strains examined were orange. P. cepacia was usually, but weakly, ornithine positive. $P$. cepacia, $P$. thomasii and $P$. pickettii grew readily on blood agar and then rapidly died.

Table $\mathrm{V}$ gives results for the two oxidative, oxidase-negative organisms studied. Because $P$. malle $i$ is very rare in clinical material in Britain, the only test necessary is the demonstration of acid production form glucose in peptone water by Acinetobacter anitratus. $P$. mallei could be further distinguished by its production of arginine dihydrolase, reduction of nitrate and failure to grow at $42^{\circ} \mathrm{C}$.

Table VI lists results for alkali-producing, oxidase-positive organisms. $P$. maltophilia was not strictly oxidase positive, because the blue colour developed only after about $10 \mathrm{~s}$, but its inclusion in this group seemed appropriate. $P$. maltophilia is often confused by the inexperienced with $P$. aeruginosa: it produces greenish colonies and has a strong ammoniacal odour. Despite its name it did not always produce acid from maltose, but it was lysine and aesculin positive; the two latter properties are rare amongst pseudomonads, although $P$. cepacia may sometimes be positive. In addition it was casein positive and sometimes grew in potassium cyanide. $P$. acidovorans and $P$. pseudoalkaligenes were the only other organisms in this group that we found commonly in our own material. The first was distinguished by its constant ability to oxidise mannitol and by the occasional production of a yellow pigment in the test for indole production (also seen with $P$. diminuta). $P$. pseudoalkaligenes was always weakly arginine positive, and often produced acid from ethanol. We found $P$. testosteroni, $P$. alkaligenes and $P$. diminuta impossible to distinguish with confidence, even with the full set of tests. Because of their rarity in our clinical material, we did not pursue the problem. $P$. putrefaciens was unmistakable in its unpleasant odour, ornithine decarboxylase activity, and its production, commonly, of hydrogen sulphide. Alkaligenes odorans was the only Alkaligenes sp. tested, and the only one that we saw in our clinical material. It had a highly characteristic fruity odour and was often $\alpha$-haemolytic. This was the only organism that we saw that reduced nitrite but not nitrate. It was otherwise non-reactive. Organisms in this group almost always produced diffusible pigments on tyrosine: the only exception among the organisms seen in clinical material was $P$. acidovorans. 
TABLE III

Oxidative, oxidase-positive, non-pigmented, arginine-positive pseudomonads

\begin{tabular}{|c|c|c|c|c|c|c|c|c|c|}
\hline Test & 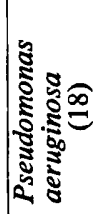 & 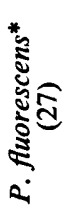 & 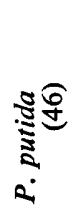 & 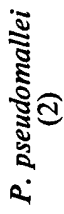 & 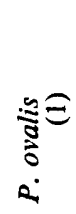 & 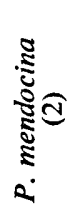 & $\underbrace{\stackrel{*}{3}}_{2^{\circ}}$ & 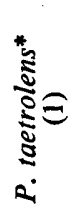 & 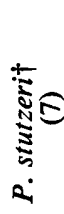 \\
\hline Ammonium salt " sugars" & & & & & & & & & \\
\hline $\begin{array}{l}\text { Dulcitol } \\
\text { Ethanol }\end{array}$ & $\bar{t}$ & - & $\overline{+}$ & \pm & - & - & $\bar{t}$ & $\bar{t}$ & $(\overline{+})$ \\
\hline Glucose & t & + & + & + & + & + & + & + & + \\
\hline Maltose & - & - & - & + & - & - & + & + & + \\
\hline Mannitol & + & V & - & + & - & - & - & + & + \\
\hline Reduction of $\mathrm{NO}_{3}$ to $\mathrm{NO}_{2}$ & + & $(-)$ & - & + & - & + & - & - & + \\
\hline Urease & + & - & - & - & - & - & - & - & - \\
\hline Gluconate & + & - & V & - & - & - & + & + & - \\
\hline Casein & + & + & - & + & + & - & - & - & - \\
\hline
\end{tabular}

Number of isolates tested is given in parenthesis.

* Little or no growth at $37^{\circ} \mathrm{C}$; tests at room temperature.

$\dagger$ Some isolates were arginine-negative.

$\mathrm{V}=$ Variable; $(+)=$ usually positive; $(-)=$ usually negative.

TABLE IV

Oxidative, oxidase-positive, non-pigmented, arginine-negative pseudomonads

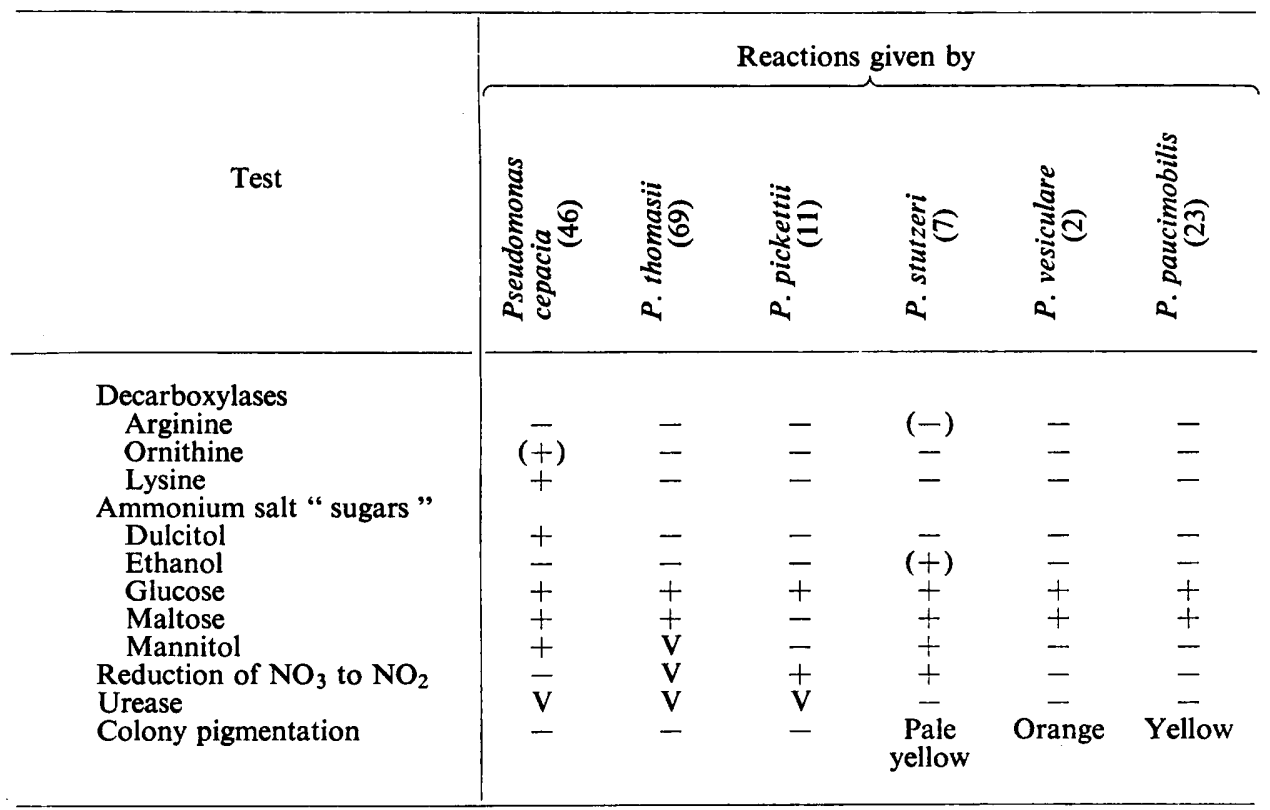

Number of isolates tested is given in parenthesis.

$\mathrm{V}=$ Variable; $(+)=$ usually positive; $(-)=$ usually negative. 
TABLE V

Oxidative, oxidase-negative, non-motile organisms

\begin{tabular}{|c|c|c|}
\hline \multirow[b]{2}{*}{ Test } & \multicolumn{2}{|c|}{ Reactions given by } \\
\hline & $\begin{array}{c}\text { Acinetobacter } \\
\text { anitratus } \\
\text { (calcoaceticus) } \\
(22)\end{array}$ & $\underset{\text { mallei }}{\text { Pseudomonas }}$ \\
\hline $\begin{array}{l}\text { Peptone water " sugars" } \\
\text { Arabinose } \\
\text { Glucose }\end{array}$ & + & $\overline{-}$ \\
\hline $\begin{array}{l}\text { Ammonium salt " sugars" } \\
\text { Arabinose } \\
\text { Ethanol } \\
\text { Glucose } \\
\text { Lactose } \\
\text { Rhamnose } \\
\text { Xylose }\end{array}$ & $\begin{array}{l}+ \\
(+) \\
+ \\
+ \\
+ \\
+\end{array}$ & $\begin{array}{l}\overline{-} \\
\pm \\
\bar{z} \\
\overline{-}\end{array}$ \\
\hline
\end{tabular}

Number of isolates tested is given in parenthesis. $(+)=$ Usually positive.

TABLE VI

Alkali-producing, oxidase-positive organisms

\begin{tabular}{|c|c|c|c|c|c|c|c|c|}
\hline Test & 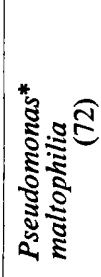 & 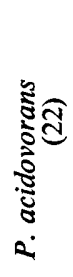 & 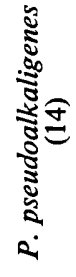 & 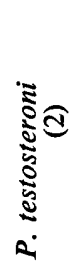 & 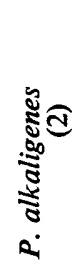 & 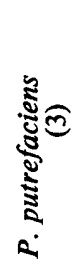 & 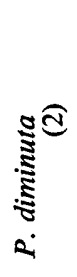 & 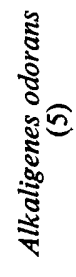 \\
\hline \multicolumn{9}{|l|}{ Ammonium salt " sugars" } \\
\hline Glucose & $( \pm)$ & - & $( \pm)$ & - & - & $\mathbf{V}$ & - & - \\
\hline Maltose & $( \pm)$ & - & $=$ & - & - & $\mathbf{V}$ & - & - \\
\hline \multirow{2}{*}{\multicolumn{9}{|c|}{ Decarboxylases }} \\
\hline & & & & & & & & \\
\hline $\begin{array}{l}\text { Arginıne } \\
\text { Lysine }\end{array}$ & $\bar{t}$ & - & \pm & $\overline{-}$ & $=$ & $\bar{z}$ & $=$ & $=$ \\
\hline Ornithine & - & - & - & - & - & + & - & - \\
\hline Reduction of $\mathrm{NO}_{3}$ to $\mathrm{NO}_{2}$ & $\mathrm{v}$ & + & + & + & V & + & - & - \\
\hline Reduction of $\mathrm{NO}_{2}$ to $\mathrm{N}_{2}$ & - & - & $(-)$ & - & - & V & - & + \\
\hline Tween 80 hydrolysis & + & \pm & - & + & + & + & - & $(-)$ \\
\hline Tween 20 hydrolysis & + & $\ddot{+}$ & - & + & + & + & + & $(-)$ \\
\hline Growth on $\beta$-hydroxybutyrate & - & + & + & + & - & - & - & + \\
\hline Citrate & - & + & + & + & $(+)$ & - & - & + \\
\hline Aesculin & + & - & - & - & - & - & - & - \\
\hline
\end{tabular}

Number of isolates tested is given in parenthesis.

* Slow oxidase positive $(10 \mathrm{~s})$.

$\mathrm{V}=$ Variable; $(+)=$ usually positive; $( \pm)=$ usually weakly positive; $(-)=$ usually negative. 
TABLE VII

Antibiotic sensitivity of some commonly isolated Pseudomonas spp.

\begin{tabular}{|c|c|c|c|c|c|c|c|c|}
\hline \multirow[b]{2}{*}{ Antibiotic } & \multicolumn{8}{|c|}{ Antibiotic sensitivity of } \\
\hline & 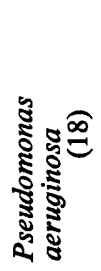 & 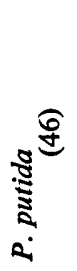 & 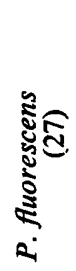 & 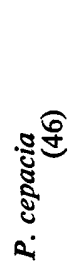 & 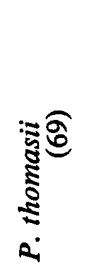 & 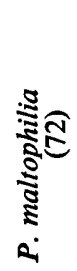 & 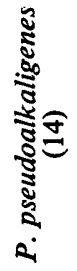 & 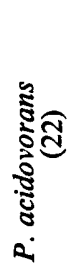 \\
\hline $\begin{array}{l}\text { Carbenicillin } \\
\text { Cephaloridine } \\
\text { Cephalothin } \\
\text { Cephalexin } \\
\text { Colistin } \\
\text { Gentamicin } \\
\text { Sulphonamide }\end{array}$ & $\begin{array}{l}(\mathbf{S}) \\
\mathbf{R} \\
\mathbf{R} \\
\mathbf{R} \\
\mathbf{S} \\
(\mathbf{S}) \\
\mathbf{R}\end{array}$ & $\begin{array}{l}\mathbf{R} \\
\mathbf{R} \\
\mathbf{R} \\
\mathbf{R} \\
\mathbf{S} \\
\mathbf{S} \\
\mathbf{R}\end{array}$ & $\begin{array}{l}\mathbf{R} \\
\mathbf{R} \\
\mathbf{R} \\
\mathbf{R} \\
\mathbf{S} \\
\mathbf{S} \\
\mathbf{S}\end{array}$ & $\begin{array}{l}\mathbf{V} \\
\mathbf{R} \\
\mathbf{R} \\
\mathbf{I} \\
\mathbf{R} \\
\mathbf{R} \\
\mathbf{S}\end{array}$ & $\begin{array}{l}\mathbf{R} \\
\mathbf{R} \\
\mathbf{I} \\
\mathbf{S} \\
\mathbf{R} \\
(\mathbf{R}) \\
\mathbf{S}\end{array}$ & $\begin{array}{l}\mathbf{S} \\
\mathbf{R} \\
\mathbf{R} \\
\mathbf{R} \\
\mathbf{S} \\
\mathbf{V} \\
\mathbf{S}\end{array}$ & $\begin{array}{l}\mathbf{S} \\
\mathbf{R} \\
\mathbf{R} \\
\mathbf{R} \\
\mathbf{V} \\
\mathbf{V} \\
\mathbf{S}\end{array}$ & $\begin{array}{l}\mathrm{V} \\
\mathrm{R} \\
\mathrm{R} \\
\mathrm{V} \\
(\mathrm{S}) \\
\mathrm{R} \\
\mathrm{S}\end{array}$ \\
\hline
\end{tabular}

Number of isolates tested is given in parenthesis.

$\mathrm{S}=$ Sensitive; $\mathrm{I}=$ intermediate; $\mathrm{R}=$ resistant $; \quad \mathrm{V}=$ variable; $\quad(\mathrm{R})=$ usually resistant; (S) = usually sensitive.

The only alkali-producing, completely oxidase-negative non-motile organism seen in clinical material was Acinetobacter lwoffii. It was identified by its strong odour of geraniums on the lysed-blood agar used for sensitivity testing and by its production of a slight alkaline change at the surface of the medium in the oxidation-fermentation test. It appeared to differ from Bordetella parapertussis, which we have not studied, in being urea negative.

Table VII lists the antibiotic sensitivity-test results found most useful as an aid to identification. Only the seven agents listed among the 13 tested appeared to give useful information.

\section{Discussion}

Much of the impetus in the study of "unusual "Gram-negative bacilli from clinical sources, came from King in Atlanta (King, 1964). Our own investigations are firmly based on her work, and subsequent revisions and extensions of it (Weaver, Tatum and Hollis, 1972; Tatum, Ewing and Weaver, 1974) and on the approach to identification in Cowan and Steel's Manual (Cowan, 1974). Our aim throughout has been to simplify and abbreviate as much as possible, in the particular context of the organisms that we have isolated in our clinical diagnostic laboratory.

We first use a preliminary screen, as advocated by Cowan and Steel, consisting of a Gram stain, growth aerobically on nutrient agar, and tests for catalase, oxidase, and oxidation-fermentation. All the organisms included in the study were Gram-negative bacilli that grew in air on nutrient agar and were catalase positive. In addition, all were either oxidative or produced alkali in the oxidation-fermentation test; none was completely non-reactive. 
On the basis of the oxidation-fermentation test and further tests for oxidase activity and motility, the organisms were allocated to one of several subgroups on the model of Cowan and Steel. However, we have found that the production of alkali in the oxidation-fermentation test is a very useful characteristic and have therefore differentiated it from the " no reaction" group of Cowan and Steel.

One of the most important innovations in taxonomic study was the introduction of substrate-utilisation tests (Jessen, 1965; Stanier, Palleroni and Doudoroff, 1972). However these tests are difficult to perform in diagnostic laboratories and a number of alternatives have been devised, especially for the study of carbohydrate metabolism. These have included the use of Hugh and Leifson's medium containing a variety of " sugars" (Weaver et al., 1972; Cowan, 1974) and the use of a variety of other basal media (Otto and Pickett, 1976).

We decided to follow the practice of the NCTC Computer Trials Laboratory, Colindale, and use ammonium salt sugars (Snell and Lapage, 1971; Snell et al., 1972; Cowan, 1974; Holmes, Lapage and Malnick, 1975) produced commercially for us as slopes in small glass screw-capped bottles (Difco).

Most of the other tests in our schemes had been devised by others, and we merely used those that seemed easiest and most reliable in a clinical setting. Thus although an assessment of the flagellar anatomy is crucial in the taxonomy of certain groups we found that flagellar stains were impractical and therefore excluded them. And although we recognised the inherent difficulties of the use of antibiotic sensitivity as a guide to identification, like Gilardi (1971b) we have used such of them as seemed useful.

In practice the scheme has worked well. $P$. aeruginosa, the commonest of these organisms, is usually easily identified on the basis of its colonial morphology and the production of characteristic pigments. There has been no difficulty in the differentiation of the common fluorescent pseudomonads by the use of only six tests and sulphonamide sensitivity has been found most useful in confirming the differentiation of $P$. putida and $P$. fluorescens. Unlike Ajello and Hoadley (1976), we saw no non-aeruginosa strains capable of growth at $42^{\circ} \mathrm{C}$.

The arginine-positive pseudomonads, including non-pigmented variants of the usually fluorescent species, were distinguished by the use of five ammonium salt "sugars" and four further tests. Arginine-negative oxidative pseudomonads were differentiated by the use of the same " sugars", two of the four further tests used for arginine-positive organisms, one additional observation on colony pigmentation, and the use of three decarboxylases.

The arginine-negative group also included almost all the brightly yellowpigmented strains that we have seen, all of which were $P$. paucimobilis (Holmes et al., 1977). We have seen very few true Flavobacterium species and no group Ve bacilli (Weaver et al., 1972).

Also included in the arginine-negative group were isolates of $P$. thomasii (Phillips et al., to be published) which we have compared in detail with $P$. pickettii (Ralston, Palleroni and Doudoroff, 1973; Riley and Weaver, 1975), 
an organism not seen in our clinical material. The original isolate of $P$. thomasii (Phillips, Eykyn and Laker, 1972) was mannitol and urease positive and nitrate negative, but we have seen isolates, believed to belong to this group, that have given the opposite results.

$P$. stutzeri was seen only once in clinical material, but was recognised without difficulty.

The remainder of these non-fermenting bacteria, all alkali-producing, have often been carelessly classified as members of the genus Alkaligenes, but this genus was seen only rarely, and as only one species ( $A$. odorans) in our material. The alkali producers required a somewhat different set of tests for their differentiation, and it has to be admitted that most of our experience has been derived from only three organisms, namely $P$. maltophilia, $P$. acidovorans and $P$. pseudoalkaligenes. $P$. putrefaciens was seen only once but was recognised without difficulty.

Our tables do not differ much in the range of tests from those of others, but we feel that the initial use of a dichotomous system results in considerable economy. Gilardi (1971a), for example, advocated over 30 tests in his simplified key, and Cowan (1974) advocated 29, while we use only 16 in our most complicated table, that for alkali-producers.

The only organism seen in the oxidative, oxidase-negative group was Ac. anitratus whose identity we now confirm merely by the demonstration of acid production in peptone-water glucose medium.

It must be made clear that we have very little experience of the genera Flavobacterium, Alkaligenes (other than Alk. odorans), Bordetella, Moraxella, Campylobacter, or Brucella, or indeed of any organisms that grow on nutrient agar but (like the last three genera above) give no reaction in oxidationfermentation medium.

A problem that we meet increasingly is the differentiation of Bacillus spp., which often closely resemble pseudomonads as they may appear consistently Gram-negative. Some produce spores on nutritionally poor media but others, particularly those that are oxidase positive and motile, may cause confusion, although they rarely correspond to any of the known pseudomonas species. Sensitivity testing is often unhelpful.

In 7 years we have identified many hundreds of non-fermenting organisms. Among these, only 15 would not have been identified to species level by the use of the abbreviated sets that we described, and of these 15, nine remain unidentified.

It may be thought that, in a clinical laboratory, the considerable effort necessary for the identification of these bacteria could be better spent. Our justification has been that all the organisms discussed in this paper, except a few included for comparative purposes, have been isolated either from patients, some of whom have suffered disease clearly related to the bacteria, or from environmental sites sampled in an effort to elucidate the epidemiology of the infections. Without accurate identification of organisms, epidemiological investigations are impossible. 


\section{SUMMARY}

Non-fermenting, catalase-positive Gram-negative bacilli that grow on nutrient agar are often isolated in clinical laboratories. We have applied biochemical techniques appropriate to a typical clinical microbiology laboratory, and for the most part described in Cowan and Steel's Manual for the identification of medical bacteria (Cowan, 1974), to 428 clinical isolates and have evolved a scheme for their identification. Organisms were subdivided into groups on the basis of three tests, namely the glucose oxidationfermentation test and tests for oxidase activity and motility. A choice was then made among other tests to produce indentification tables, containing only the most useful tests, for the various groups. The most complicated table has only 16 tests.

This simple system identified $96.5 \%$ of the 428 organisms, as well as many subsequent isolates of the more common organisms.

We gratefully acknowledge the invaluable help and advice that we have received from Mr B. Holmes and Dr S. P. Lapage of the Computer Trials Laboratory, National Collection of Type Cultures, Colindale, London, and from Dr R. E. Weaver of the Center for Disease Control, Atlanta, Georgia.

\section{REFERENCES}

Ajello, G. W. ANd Hoadley, A. W. 1976. Fluorescent Pseudomonads capable of growth at $41^{\circ} \mathrm{C}$ but distinct from Pseudomonas aeruginosa. J. clin. Microbiol., 4, 443.

Cowan, S. T. 1974. Cowan and Steel's Manual for the identification of medical bacteria, 2nd ed., Cambridge.

Gilardi, G. L. 1971a. Characterization of Pseudomonas species isolated from clinical specimens. Appl. Microbiol., $21,414$.

GILARDI, G. L. 1971b. Antimicrobial susceptibility as a diagnostic aid in the identification of non-fermenting Gram-negative bacteria. Appl. Microbiol., 22, 821.

Holmes, B., Lapage, S. P. and Malnick, H. 1975. Strains of Pseudomonas putrefaciens from clinical material. J. clin. Path., 28, 149.

Holmes, B., Owen, R. J., Evans, A., Malnick, H. And Willcox, W. R. 1977. Pseudomonas paucimobilis, a new species isolated from human clinical specimens, the hospital environment, and other sources. Int. J. syst. Bact., 27, 133.

JESSEN, O. 1965. Pseudomonas aeruginosa and other green fluorescent Pseudomonads. A taxonomic study. Copenhagen.

KING, E. O. 1964. The identification of unusual pathogenic Gram-negative bacteria. US Dept Hlth, Educ. Welf., Center for Disease Control, Atlanta, Georgia.

Otto, L. A. AND Picketr, M. L. 1976. Rapid method for identification of Gram-negative nonfermentative bacilli. J. clin. Microbiol., 3, 566.

OWENS, J. D. AND KedDIE, R. M. 1968. A note on the vitamin requirements of some coryneform bacteria from soil and herbage. J. appl. Bact., 31, 344.

Phillips, I., Eykyn, S. And Laker, M. 1972. Outbreak of hospital infection caused by contaminated autoclaved fluids. Lancet, 1, 1258.

Ralston, E., Palleroni, N. J. and Doudoroff, M. 1973. Pseudomonas picketti, a new species of clinical origin related to Pseudomonas solanacearum. Int. J. syst. Bact., 23, 15.

Riley, P. S. ANd Weaver, R. E. 1975. Recognition of Pseudomonas pickettii in the clinical laboratory: Biochemical characterization of 62 strains. J. clin. Microbiol., 1, 61 .

Snell, J. J. S., Hill, L. R., Lapage, S. P. and Curtis, M. A. 1972. Identification of Pseudomonas cepacia Burkholder and its synonymy with Pseudomonas kingii Jonsson. Int. J. syst. Bact., 22, 127. 
SNell, J. J. S. AND LAPAGE, S. P. 1971. Comparison of four methods for demonstrating glucose breakdown by bacteria. J. gen. Microbiol., 68, 221.

Stanier, R. Y., Palleroni, N. J. and Doudoroff, M. 1966. The aerobic Pseudomonads: a taxonomic study. J. gen. Microbiol., 43, 159.

TAtum, H. W., Ewing, W. H. AND Weaver, R. E. 1974. Miscellaneous Gram-negative bacteria. In Manual of clinical microbiology, 2nd ed., edited by E. H. Lennette, E. H. Spaulding and J. P. Truant, Washington, p. 270.

Weaver, R. E., TAtum, H. W. and Hollis, D. G. 1972. The identification of unusual pathogenic Gram-negative bacteria. US Dept Hlth Educ. Welf., Center for Disease Control, Atlanta, Georgia. 